Article

\title{
Estimating the Possibility of Surface Soil Pollution with Atmospheric Lead Deposits Using the ADMER Model
}

\author{
Binh Nguyen Thi Lan, Takeshi Kobayashi *, Atsushi Suetsugu, Xiaowei Tian and \\ Takashi Kameya \\ Department of Risk Management and Environmental Sciences, Yokohama National University, Yokohama \\ 240-8501, Japan; nguyen-binh-zh@ynu.jp (B.N.T.L.); suetsugu-atsushi-pc@ynu.ac.jp (A.S.); \\ tian-xiaowei-gx@ynu.ac.jp (X.T.); kameya-takashi-px@ynu.ac.jp (T.K.) \\ * Correspondence: kobayashi-takeshi-bj@ynu.ac.jp; Tel.: +81-45-339-3775
}

Received: 3 January 2018; Accepted: 28 February 2018; Published: 6 March 2018

\begin{abstract}
The literature assessing the risks of soil pollution from atmospheric lead ( $\mathrm{Pb})$ deposition is still insufficient, given that $\mathrm{Pb}$ deposition can cause large-scale surface soil pollution. This study estimated the possibility of $\mathrm{Pb}$ deposition causing soil pollution by calibrating a numerical model of deposition flux with a measured $\mathrm{Pb}$ content dataset in proximity to a pollution source. A total 34 surface soil samples were collected around an industrial park that emits $\mathrm{Pb}$ into the atmosphere. The sample's $\mathrm{Pb}$ content was determined using hydrochloric acid extraction and an ICP-MS. The amount of annual $\mathrm{Pb}$ deposition was estimated using the atmospheric dispersion model for exposure and risk assessment (ADMER model). This approach resulted in accurate predictions of $\mathrm{Pb}$ distribution for most sites ( $<800 \mathrm{~m}$ from the pollution source), but the results indicated that the dry deposition velocity of $\mathrm{Pb}$-containing particles was a significant determinant of horizontal $\mathrm{Pb}$ distribution. We conducted a sensitivity analysis of the ADMER's estimated $\mathrm{Pb}$ deposition flux values by changing the diameter of $\mathrm{Pb}$-containing particles. This analysis showed large fluctuations in soil $\mathrm{Pb}$ content within $1 \mathrm{~km}$ of the source, within the range of the previously reported dry deposition velocity.
\end{abstract}

Keywords: atmospheric lead deposition; surface soil pollution; Pb particles; ADMER model; PRTR

\section{Introduction}

According to a report from the Japanese Ministry of the Environment, in most cases of soil pollution, the causes could not be specified [1]. Among cases with unknown causes, $71 \%$ were polluted by heavy metals, and the most frequent pollutant was $\mathrm{Pb}$ [1]. According to Japan's established Pollutant Release and Transfer Register system (PRTR) data [2], the amount of Pb discharged in Japan during the 2015 fiscal year was approximately $7.0 \mathrm{Mg}$ for the atmospheric environment. The deposition of $\mathrm{Pb}$ from the atmosphere could increase the risk of its direct inhalation and affect the quality of surface soils [3-5]. We estimate that the 7.0 Mg of atmospheric Pb pollutes ca. $2.3 \mathrm{~km}^{2}$ of surface soil $(0-2 \mathrm{~cm}$ depth, $1 \mathrm{~g} \mathrm{~cm}^{-3}$ bulk density) with $\mathrm{Pb}$ to Japan's legal limit (150 $\mathrm{mg} \mathrm{Pb} \mathrm{kg}^{-1}$ dry soil) every year. Elemental, sulfate, and carbonate forms of $\mathrm{Pb}$, which have low solubility in water, are commonly found in the atmosphere, and most ionized $\mathrm{Pb}$ can be adsorbed on soil minerals [6]. Therefore, the $\mathrm{Pb}$ species can accumulate within surface soil $[7,8]$, and the possibility of deposition on ground surfaces should be carefully assessed.

Concerning the path of contamination by deposition, the spatial distribution of heavy metals has been reported on surface soils around a cement factory [9]. Krishna et al. investigated the spatial distribution of $\mathrm{Pb}$ in surface soils around a factory, and differentiated the effects of industrial activity on surface ground pollution from the impacts of pollution from natural sources [10]. Soriano et al. 
confirmed the soil pollution from atmospheric deposition by analyzing heavy metals in particles collected by an air sampler [11]; Qiao et al. reported that soil type was a main factor influencing the migration of As, Pb, and Cd in rainfall, based on Geographical Detector Software [12]; and Kobayashi et al. reported that the adsorption and elution of metals from contaminated soil was influenced by $\mathrm{pH}$, content of humic substances, and salt concentration [13]. Therefore, depending on the environmental factors mentioned above, various heavy metals forms can stay on the soil surface or migrate along the soil profile. Other studies have also shown that soil pollution can be caused by deposition of heavy metals from the atmosphere [14-18]. For soil and groundwater protection, it therefore important to consider the soil contamination due to heavy metals deposition from the atmosphere, but this input to soil pollution is still not emphasized in environmental assessment and management practices of polluted sites.

Specifically, $\mathrm{Pb}$ deposition has not been assessed due to the lack of verification data on the tools used for linking large-scale meteorological data and atmospheric $\mathrm{Pb}$ deposition. There have been some efforts to estimate the spatial distribution of polluted sites by modeling dispersion and deposition of atmospheric pollutants [19-23]. The atmospheric dispersion model for exposure and risk assessment (ADMER model) is a series of models and systems designed for estimating atmospheric levels of chemicals and assessing their exposure. It uses data from various sources-Google Earth ${ }^{\mathrm{TM}}$ maps, the automated meteorological data acquisition system (AMeDAS), the PRTR, and other statistics (e.g., traffic, population)—in a single interface [24,25]. The ADMER is a puff-plume model that simulates the dispersion of atmospheric pollutants from their emission sources and evaluates dry deposition and washout of atmospheric pollutants at 100-m resolution [24,25]. The ADMER has been verified for various pollutants (e.g., 1, 3-butadiene [26]), but it has not yet been evaluated based on its estimation of the horizontal distribution of $\mathrm{Pb}$ deposited on ground surfaces. Nor has it been evaluated with a precise dataset showing the $\mathrm{Pb}$ content of surface soil samples.

The aim of this study, illustrated in Figure 1, was to evaluate the contribution of atmospheric $\mathrm{Pb}$ deposition potential on pollution of a soil surrounding an industrial site. First, we measured the soil $\mathrm{Pb}$ concentration around the industry emitting $\mathrm{Pb}$. Then, the ADMER model was used to estimate the distribution of annual deposition flux in the soil where the emitted $\mathrm{Pb}$ settled. Third, the estimated horizontal distribution of $\mathrm{Pb}$ deposition and the measured $\mathrm{Pb}$ content of the surface soil were compared to optimal estimates of atmospheric $\mathrm{Pb}$ deposition. Furthermore, because the parameter values entered into the ADMER model could have a significant influence on the deposition flux to soil surface calculation results, we compared the estimated results of the deposition flux with meteorological data and $\mathrm{Pb}$-containing particle diameters.

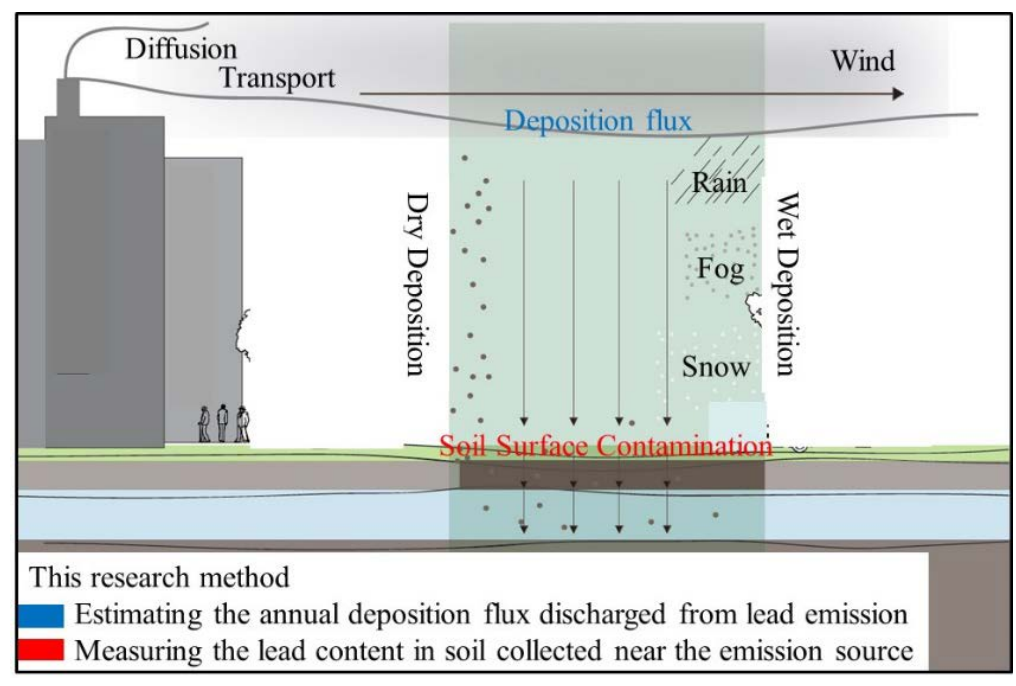

Figure 1. Processes included in the estimation of deposition flux. 


\section{Materials and Methods}

\subsection{Study Area and Sampling Techniques}

An intensive source of aerosol-form $\mathrm{Pb}$ emissions was located in the park (Figure 2). The study area, illustrated in Figure 2, was selected by searching the established survey data in the PRTR system [27] from April 2001 to March 2015 (2001-2014 fiscal years). For 2010-2014 the amount of released $\mathrm{Pb}$ was calculated from the PRTR $\mathrm{Pb}$ compounds data with conversion factors for the $\mathrm{Pb}$ compounds, while for 2001-2009 we used reported PRTR Pb data. In the 2001-2014 fiscal years, the selected factory discharged $\mathrm{Pb}$ into the atmosphere at rates of $500-5500 \mathrm{~kg}_{\text {year }}{ }^{-1}$. This factory had been conducting $\mathrm{Pb}$ emitting in the vicinity of residential areas (apartments, schools, parks, etc.) for many decades. Surface soil samples were collected from 34 sites within the study area (Figure 2) at a depth of $0-2 \mathrm{~cm}$, and then fine particles were collected for $\mathrm{Pb}$ analysis using a sieve with 2-mm openings. Each of the analytical samples was stored in a 50-mL polypropylene bottle.

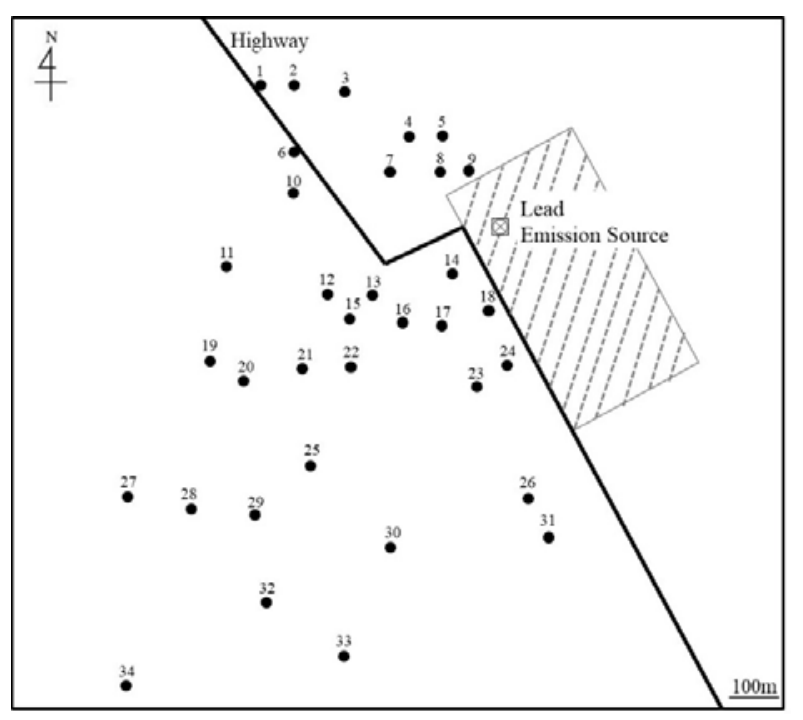

Figure 2. The location of soil sampling sites around industrial park.

\subsection{Measurement of Lead Content in Soil Samples}

In this study, the $\mathrm{Pb}$ content of each of the surface soil samples was measured in order to monitor the horizontal distribution of polluted soil. We included the legal limit for $\mathrm{Pb}$ in soil (150 $\mathrm{mg} \mathrm{kg}^{-1}$ [28]) in our visualization of the horizontal distribution results. Each extract solution of $\mathrm{Pb}$ was made in accordance with the Japanese Ministry of the Environment's Notification No. 19 [29]. Then, the Pb content of the solution was measured using an inductively coupled plasma mass spectrometer (ICP-MS, ELAN DRC-e, Perkin Elmer, Ltd., Waltham, MA, USA). The Pb content $\left(\mathrm{mg} \mathrm{kg}^{-1}\right)$ of each soil sample was calculated based on ICP-MS results. Six grams (dry matter basis) of each soil sample was mixed with $200 \mathrm{~g}$ of $1 \mathrm{M} \mathrm{HCl}$ in a 500-mL polypropylene bottle, and the suspension was shaken reciprocally for two hours at 200 strokes per minute at room temperature (Figure 3). After shaking, the mixture was left undisturbed for $20 \mathrm{~min}$ so that the supernatant could be collected. The supernatant was then purified by centrifugation at $3000 \mathrm{rpm}(1510 \times \mathrm{g})$ for $20 \mathrm{~min}$ and filtered with a $0.45-\mu \mathrm{m}$ pore size membrane filter (Membrane Solutions, Tokyo, Japan). Finally, the Pb content of the test solution was determined by the ICP-MS. 


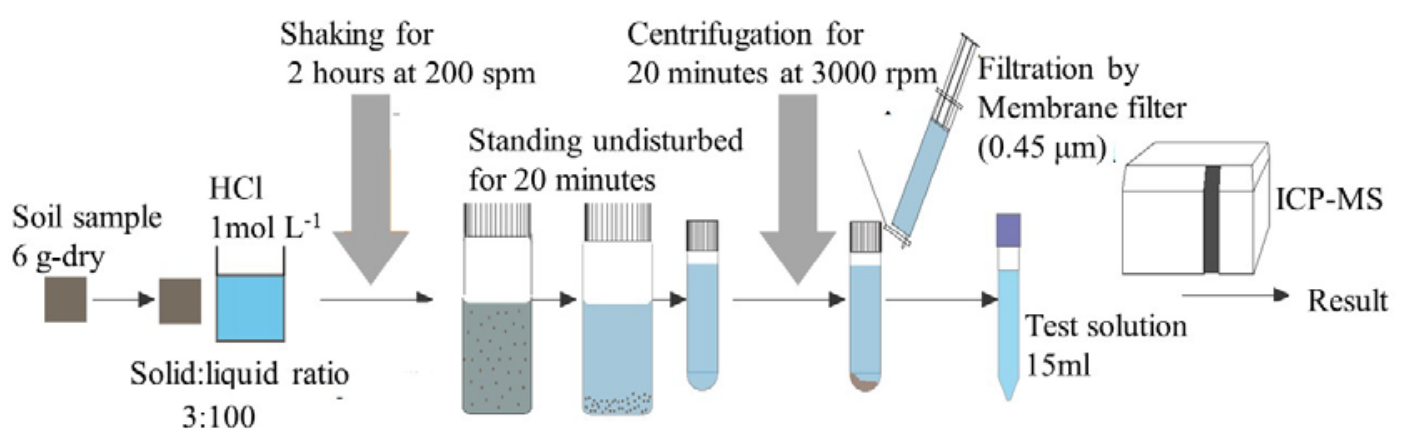

Figure 3. Method for measuring $\mathrm{Pb}$ content.

\subsection{Estimation of Annual Deposition Flux Using ADMER}

To determine whether atmospheric deposition is the cause of the soil's $\mathrm{Pb}$ pollution, we compared the observed distribution of $\mathrm{Pb}$ content in the soil near the source factory with an atmospheric dispersion model's estimated distribution of $\mathrm{Pb}$ deposition. In the estimation of the deposition flux, the ADMER model version 2.6.0 was used [30]. This model estimates the atmospheric concentrations of chemical substances as well as the deposition flux in surface soil at 100-m horizontal resolution. As shown in Figure 4, in order to obtain the annual atmospheric deposition flux using the ADMER model, we prepared the input data, executed a $\mathrm{Pb}$ deposition simulation, confirmed all calculations, and analyzed our data based on the results of the estimation. In the estimation, we used data from meteorological stations close to the sampling area, the map of the around the $\mathrm{Pb}$ emission site, and the PRTR on atmospheric Pb emissions. We used degradation rate, background concentration, dry deposition velocity, and scavenging ratio as input parameters in estimating $\mathrm{Pb}$ deposition using the ADMER model. We assumed that Pb-particles discharged from the factory did not decompose in the atmosphere under normal conditions (radioactive decay in ${ }^{204} \mathrm{~Pb} /{ }^{205} \mathrm{~Pb} /{ }^{210} \mathrm{~Pb}$ was considered to be negligible for the estimation of total $\mathrm{Pb}$ deposition). Thus, we set the degradation rate at zero. The background concentration was assumed to be zero because the natural concentration of $\mathrm{Pb}$ in the atmosphere was negligible compared to concentrations seen around the factory [31]. For example, in 2004, the annual average $\mathrm{Pb}$ concentration in 15 countries of the European Union ranged from 0.63 to $12.8 \mathrm{ng} \mathrm{m}^{-3}$ [32], and was $0.076 \mathrm{ng} \mathrm{m}^{-3}\left(76 \mathrm{pg} \mathrm{m}^{-3}\right)$ in Antarctica [33]. In order to elucidate the influence of the source factory, we omitted background $\mathrm{Pb}$ aerosols from our visualizations.

Because no data on the particle size emitted from the factory were available and we could not measure the particle size of the emitted particulate $\mathrm{Pb}$ to analyze the ADMER model's sensitivity, we assumed the velocity of particulate $\mathrm{Pb}$ dry deposition in the range of 0.35 to $1.75 \mathrm{~cm} \mathrm{~s}^{-1}$ corresponding to particle diameters of 6.1-9.5 $\mu \mathrm{m}[34,35]$. Sakata \& Marumoto [34] reported that the washout ratio for $\mathrm{Pb}$ species (the ratio between the wet deposition velocity and the precipitation intensity/atmospheric concentration) was in the range of 87-119; therefore, the average value of 104 was used for the estimation of $\mathrm{Pb}$ horizontal distribution. The ADMER model calculations were done for a five $\mathrm{km}^{2}$ area around the factory ( $\mathrm{Pb}$ source) at 100-m horizontal resolution. 


\begin{tabular}{|c|c|}
\hline Preparation for Calculation & \multirow{5}{*}{$\begin{array}{l}\text { 1. Target substance : } \mathrm{Pb} \\
\text { 2. Calculationrange : } 5 \mathrm{~km} \times 5 \mathrm{~km} \\
\text { 3. Meteorological data } \\
\text { AMeDAS (Meteorological data from } 2001 \text { to } 2014 \text { year) } \\
\text { 4. Emission grid data } \\
\text { The emission of lead that discharged into the atmosphere } \\
\text { from PRTR emission data }\end{array}$} \\
\hline Generation and selection of a target calculation range & \\
\hline & \\
\hline Generation of meteorological data in the target range & \\
\hline Generation of emission grid data for a target substance & \\
\hline Performing Calculation & \multirow{4}{*}{$\begin{array}{l}\text { Calculation parameters } \\
\text { 1. Degradation rate : } 0.00 \mathrm{sec}^{-1} \\
\text { 2. Background concentration }: 0.00 \mathrm{~g} \mathrm{~m}^{-3} \\
\text { 3. Dry deposition rate : } 0.35-1.75 \mathrm{~cm} \mathrm{~s}^{-1} \\
\text { 4. Scavenging ratio : } 104(-)\end{array}$} \\
\hline Confirmation of data to be used for calculation & \\
\hline Generation of a calculation case & \\
\hline Performing calculation & \\
\hline Confirmation and Analysis on the Calculation Results & \multirow{3}{*}{$\begin{array}{l}\text { Calculation results } \\
\text { 1. Confirmation of the total deposition flux } \\
\text { 2. Assessment of the relationship of } \\
\text { the estimated concentration and } \\
\text { the actual measured concentration of lead in soil }\end{array}$} \\
\hline Confirmation of the calculation results & \\
\hline Analysis using the calculation results & \\
\hline
\end{tabular}

Figure 4. The general flow of the ADMER analysis process.

\section{Results and Discussion}

\subsection{Lead Content in Soil}

$\mathrm{Pb}$ concentration in the surface soil samples is shown in Figure 5. Among the samples, 20 samples (59\%) had $\mathrm{Pb}$ concentrations exceeding Japan's legal limit (150 $\left.\mathrm{mg} \mathrm{kg}^{-1}\right), 8$ samples had values in the range of $50-100 \%$ of the limit, and 1 sample had a concentration lower than $20 \%$ of the limit (Figure 5). Although the legal limit has been set as a vertical average over the $0-5 \mathrm{~cm}$ and $5-50 \mathrm{~cm}$ of soil depth [36], intensive surface soil (which we define as the top $2 \mathrm{~cm}$ of soil) pollution should be evaluated using a prognostic approach for factories operating over long periods of time. Furthermore, it was noted that a few sites were polluted despite being far from the source factory (several hundred meters away).

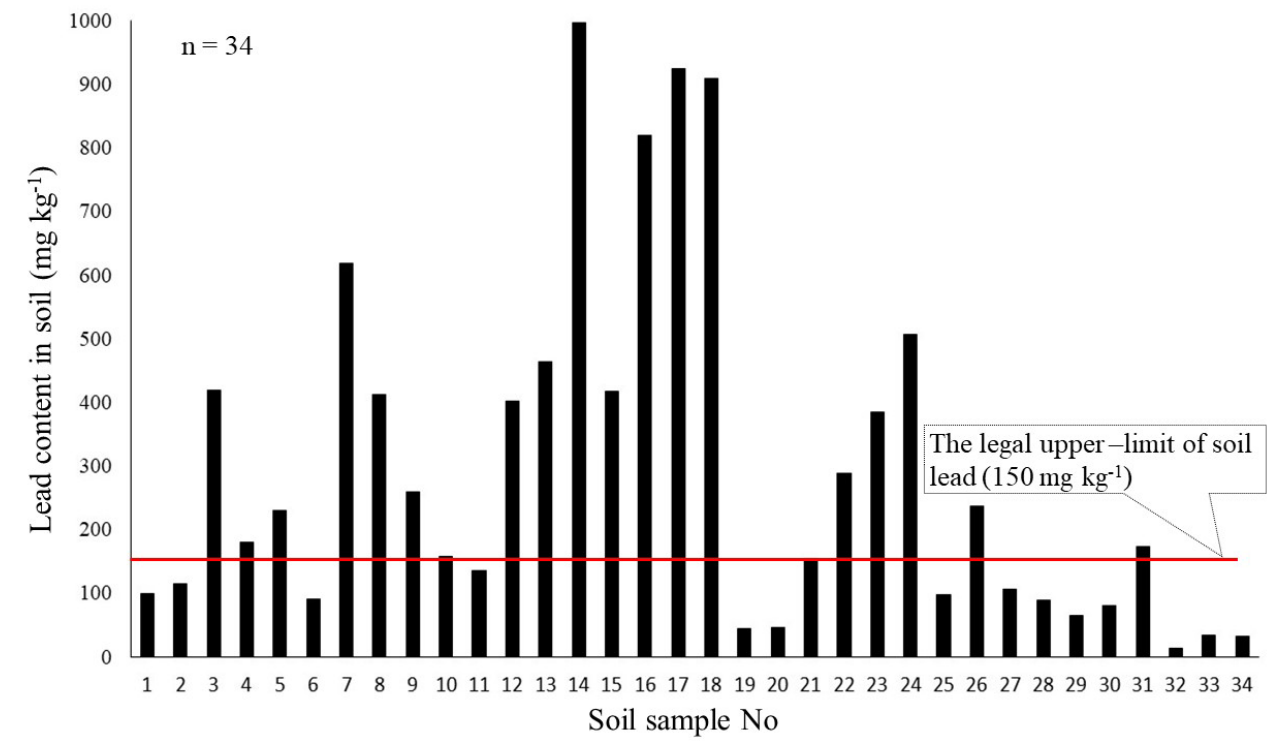

Figure 5. Pb content of surface soil samples. 


\subsection{ADMER and Field Measurement Calculation Results—Comparison E Discussion}

First, we compared the measured and the estimated $\mathrm{Pb}$ distribution with the average dry deposition velocity $\left(1.05 \mathrm{~cm} \mathrm{~s}^{-1}\right)$ of the reported values $\left(0.35-1.75 \mathrm{~cm} \mathrm{~s}^{-1}\right)$ using the ADMER model, using the PRTR data of the year with the highest $\mathrm{Pb}$ emission $\left(5500 \mathrm{~kg}\right.$ year $\left.{ }^{-1}\right)$ between 2001 and 2014 (Figure 6). Measured Pb concentration in soil and the estimated results using PRTR data from 14 consecutive years are shown in Figure 7. In most of the samples with high estimated annual deposition flux, the measured $\mathrm{Pb}$ concentration was also high, and both estimated and measured $\mathrm{Pb}$ distribution showed that $\mathrm{Pb}$ deposition decreased with the distance from the emission source (Figures 6 and 7). Even at distances of 400 to $500 \mathrm{~m}$ from the source, where there a lower soil pollution could be expected, the $\mathrm{Pb}$ concentrations in the surface soil exceeded the legal limit, further indicating atmospheric $\mathrm{Pb}$ deposition. The relationship between the estimated cumulative $\mathrm{Pb}$ deposition flux over $14 \mathrm{y}$ and the soil $\mathrm{Pb}$ concentration is shown in Figure 8 . Measured $\mathrm{Pb}$ concentrations in soil is influenced by environmental factors such as soil erosion, $\mathrm{Pb}$ adsorption onto soil solid phases, soil $\mathrm{pH}$ value, salinity, and humic substances content, which control the $\mathrm{Pb}$ solubility and mobility in soil over time. Also PRTR data, particle size, and meteorological change influence the estimated total $\mathrm{Pb}$ deposition flux by over time using ADMER model ( $x$-axis). Use of the ADMER model to estimate the total deposition flux does not take into account the factors on the $y$-axis. We found a quasi linear relationship in the scatter plot of measured and estimated results (Figure 8), but the deviation of the correlation coefficient value was large due to the variability of the above mentioned environmental factors regulating the $\mathrm{Pb}$. In this study, we analyzed the factors that have significant impact on the estimated $\mathrm{Pb}$ deposition flux by using ADMER model as the following Sections 3.3 and 3.4. The relationship between the estimated cumulative $\mathrm{Pb}$ deposition flux over $14 \mathrm{y}$ and the soil $\mathrm{Pb}$ concentration at the corresponding location is shown in Figure 8. Annual climate fluctuations could explain this deviation, but other factors could be also important for the variation in $\mathrm{Pb}$ deposition results such as heterogeneity in the size of the $\mathrm{Pb}$-containing particles, chemical reactions causing alterations in particle density or water solubility, and need further evaluation for improving simulation. In Figure 8, two separate classes corresponding to plots with large (class 1 ) and small (class 2) annual deposition fluxes, respectively. Most of the class 1 sites were closer to the emission source, compared with class 2 sites, and the threshold values of the $\mathrm{Pb}$ deposition of the two classes were ca. $200 \mathrm{mg} \mathrm{m}^{-2}$ year $^{-1}$ flux (Figure 6). The low $\mathrm{Pb}$ content of soil samples taken from remote sites (class 2) could be also related to differences in particle diameter. The fixed diameter of $\mathrm{Pb}$-containing particles in the calculation of dry deposition velocity was likely responsible for the difference between the measured and estimated results in the Pb distribution in the polluted sites. Further, at sampling sites 3, 23, and 26, the deposition simulation did not explain the high $\mathrm{Pb}$ concentrations, which could be possibly due to long-distance migration of $\mathrm{Pb}$ from other sources (e.g., surrounding buildings), or deposition before the registration of PRTR data. 


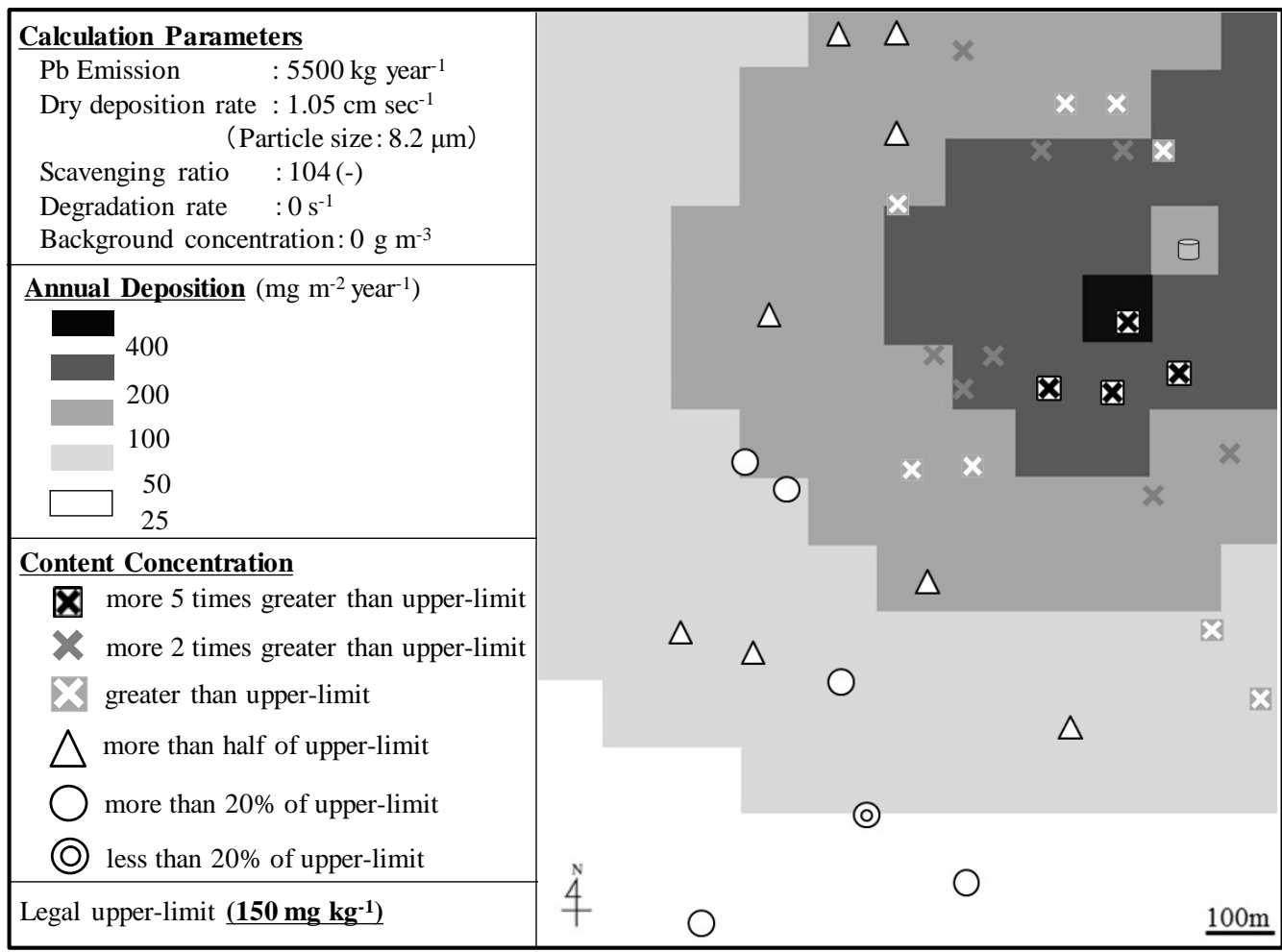

Figure 6. Results of soil's measured $\mathrm{Pb}$ content and annual estimated deposition flux.

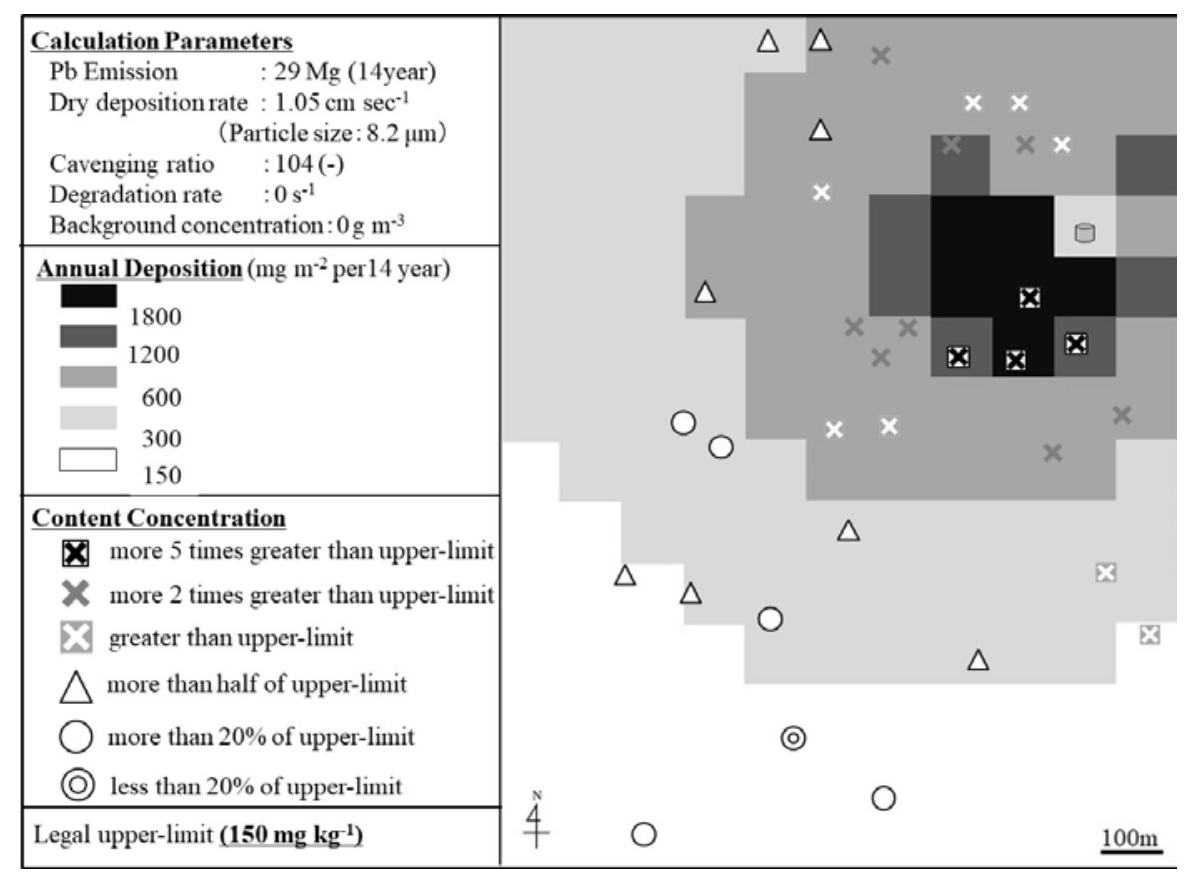

Figure 7. Results of soil's measured $\mathrm{Pb}$ content and estimated deposition flux over 14 years. 


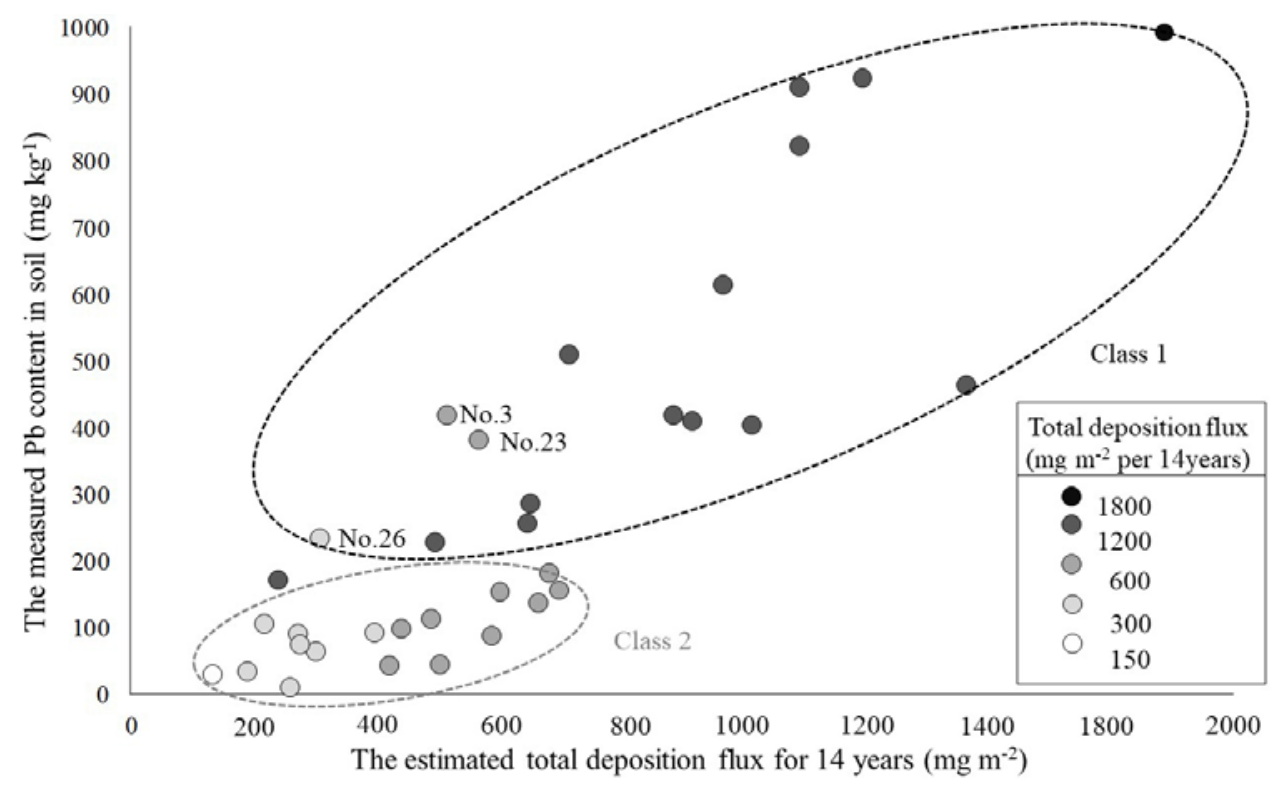

Figure 8. The relationship between total deposition flux and soil's measured Pb content.

\subsection{Sensitivity Analysis of Estimated Lead Deposition Flux Using Varied Dry Deposition Velocities}

By considering the particle size as a significant factor that has significant impact on the variation on the $x$-axis of Figure 8, to determine the effect of particle size on the simulated $\mathrm{Pb}$ deposition results, in the estimation of $\mathrm{Pb}$ deposition we fixed the input data except for dry deposition velocity. We used AMeDAS and PRTR data from 2004 when the highest atmospheric Pb emission was reported (5500 kg year $\left.^{-1}\right)$. Then we used the ADMER model to calculate the annual $\mathrm{Pb}$ deposition with varied particle diameters $(6.1,7.6,8.2,9$, and $9.5 \mu \mathrm{m})$ at 100-m resolution. These particle diameters corresponded to dry deposition velocity rates of $0.35,0.7,1.05,1.4$, and $1.75 \mathrm{~cm} \mathrm{~s}^{-1}$, and the results are shown in Figure 9. Based on the results, we concluded that the larger the diameter of emitted $\mathrm{Pb}$ particles, the larger the expected deposition flux on the ground surface. However, the area nearest to the source $(100-200 \mathrm{~m})$ received the largest deposition flux, regardless of the diameter of $\mathrm{Pb}$-containing particles. The estimated total deposition flux increases by approximately 5 times when the $\mathrm{Pb}$ particle size increases approximately 1.6 times, and furthermore, at a distance of $1 \mathrm{~km}$ from the emission source, this correlation did not change, regardless of the distance from the source. Although in this study the $\mathrm{Pb}$ particle size was a hypothetical value, the results showed that the $\mathrm{Pb}$ particle size has a great impact on the estimated total deposition flux but did not affect the concentration distribution. This indicated that the concentration distribution was calculated by a single particle size did not significantly affect the deviation of the distribution between the measured value and the estimated value. The present version of the ADMER model does not perform deposition calculations at resolution lower than $100 \mathrm{~m}$, and therefore we may be observing effects at insufficient resolution.

As far as the horizontal distribution of $\mathrm{Pb}$ in soil using different particle sizes is concerned, for the same amount of total $\mathrm{Pb}$ emitted, the larger was the particle size of $\mathrm{Pb}$ aerosols, the larger was the observed numbers of mesh (a unit of $100 \mathrm{~m}^{2}$ ) within $1 \mathrm{~km}$ of the factory with a high deposition flux (Figure 10). Among highly polluted sites (deposition flux $>100 \mathrm{mg} \mathrm{m}^{-2}$ year $^{-1}$ ), for $\mathrm{Pb}$ particle diameter of $6.1 \mu \mathrm{m}$ the polluted area extended to $250-\mathrm{m}$ from the emission source. Analogously, when $\mathrm{Pb}$ particles had diameters of 7.6, 8.2, 9, and $9.5 \mu \mathrm{m}$, the highly polluted sites extended 660, 845, 1050, and $1150 \mathrm{~m}$ from the emission source. In the simulation, the highest deposition flux was also increased by increasing the diameter of Pb-containing particles (flux of 154, 307, 459, 612, and $763 \mathrm{mg} \mathrm{m}^{-2}$ year $^{-1}$ for $6.1,7.6,8.2,9$, and $9.5 \mu \mathrm{m}$ diameters). It was confirmed that even a minor change in the particle size of $\mathrm{Pb}$ particle diameter (e.g., from 6.1 to $9.5 \mu \mathrm{m}$, a 1.6 times increase) intensifies the $\mathrm{Pb}$ deposition flux (from 154 to $763 \mathrm{mg} \mathrm{m}^{-2}$ year $^{-1}$, a 5.0 times increase). Based on these results, it is crucial to monitor 
deposition flux and polluted area distribution in order to optimize dry deposition velocity, which can help prevent surface soil from being polluted by $\mathrm{Pb}$ aerosol deposition.

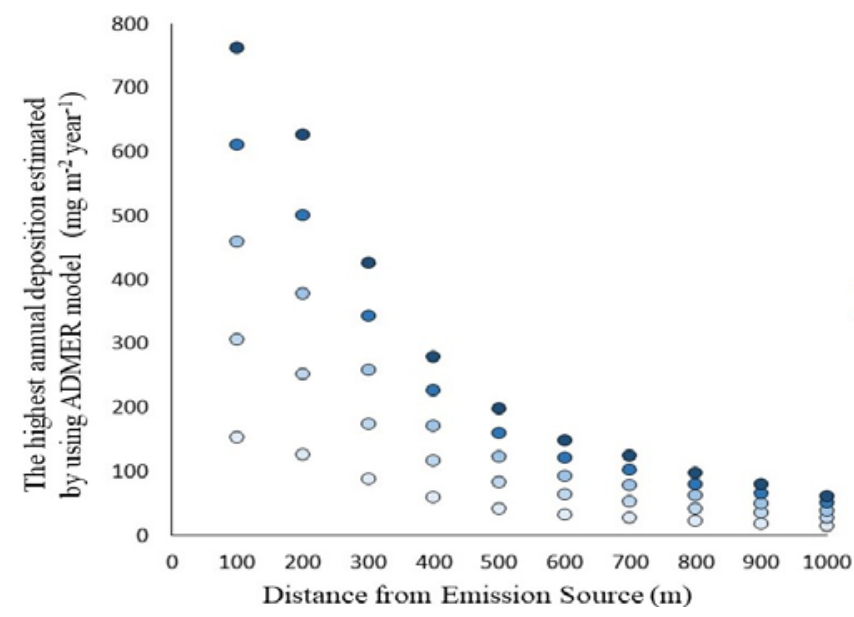

\begin{tabular}{|cc|c|}
\hline \multicolumn{2}{|c|}{$\begin{array}{c}\text { Dry deposition rate } \\
\left(\mathrm{cm} \mathrm{s}^{-1}\right)\end{array}$} & $\begin{array}{c}\text { Particle size } \\
(\mu \mathrm{mm})\end{array}$ \\
\hline$\bigcirc$ & 0.35 & 6.1 \\
\hline$\bigcirc$ & 0.70 & 7.6 \\
\hline$\bigcirc$ & 1.05 & 8.2 \\
\hline$\bigcirc$ & 1.40 & 9.0 \\
\hline$\bigcirc$ & 1.75 & 9.5 \\
\hline
\end{tabular}

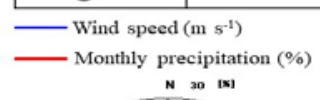

Distance from Emission Source (m)

Figure 9. Estimated deposition flux at sites various distances from the emission source.

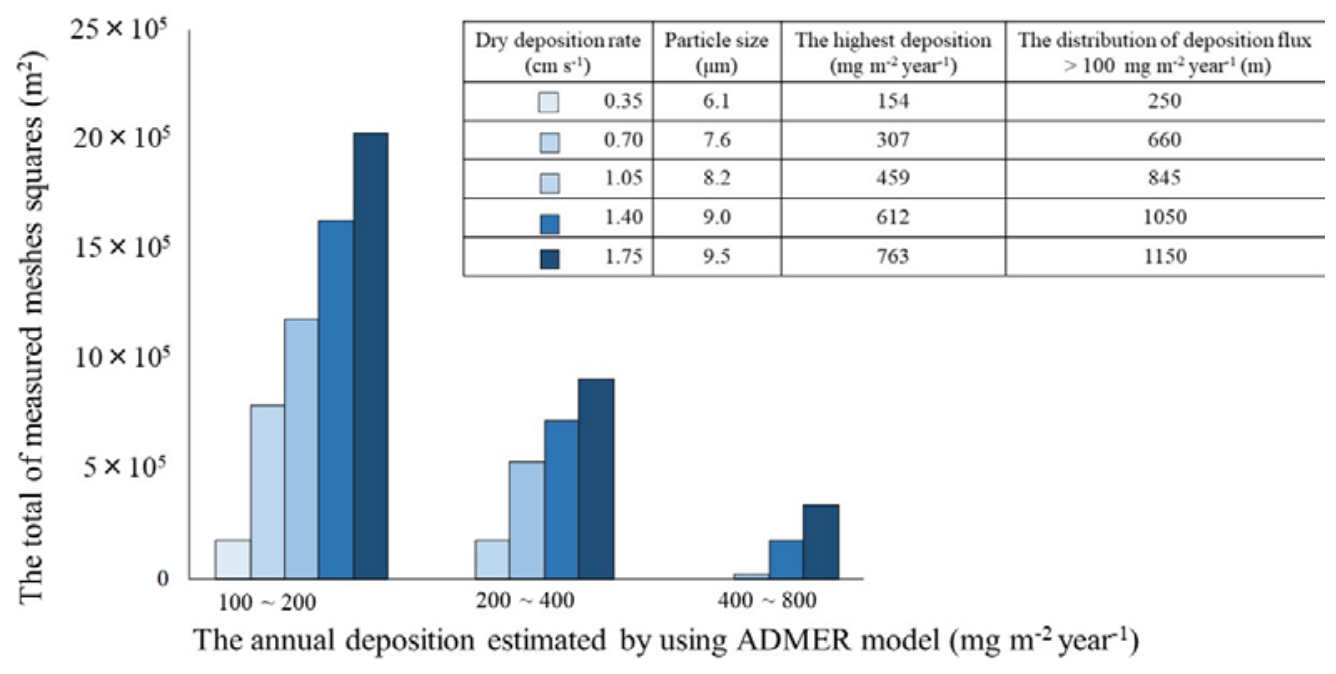

Figure 10. The distribution of meshes with a high deposition flux by particle size.

\subsection{Differences in Estimated Deposition due to Annual Climate Fluctuations}

Meteorological data can change $\mathrm{Pb}$ deposition results when it deviates from averaged climate parameter values, and we investigated variations in atmospheric deposition flux due to annual climate fluctuations. To predict the range of variation in $\mathrm{Pb}$ deposition flux, we used the highest annual atmospheric $\mathrm{Pb}$ emission in recent years $\left(5500 \mathrm{~kg}_{\text {year }}{ }^{-1}\right)$. Then, we performed simulation of $\mathrm{Pb}$ deposition using $14 \mathrm{y}$ of data from the AMeDAS database providing an estimate of annual fluctuation in the highest deposition flux at 100-m resolution. The mesh with the highest annual deposition was selected and used to evaluate the worst case of fluctuation in the deposition estimation. Figure 11 shows the annual variation in deposition flux due to climate fluctuations. The standard variation in annual deposition for the 14 years was $7.24 \mathrm{mg} \mathrm{m}^{-2}$ year $^{-1}$, and the coefficient of variation (CV) was 5.6. Based on the results, we concluded that annual climate fluctuation data should be included in precise deposition flux estimates. Therefore, it is necessary to consider the range of fluctuation in climate data. The variation in deposition flux caused by climate fluctuation was not large in the present study, but verification of the model with a series of long-term meteorological data is necessary for other factories and regions. 


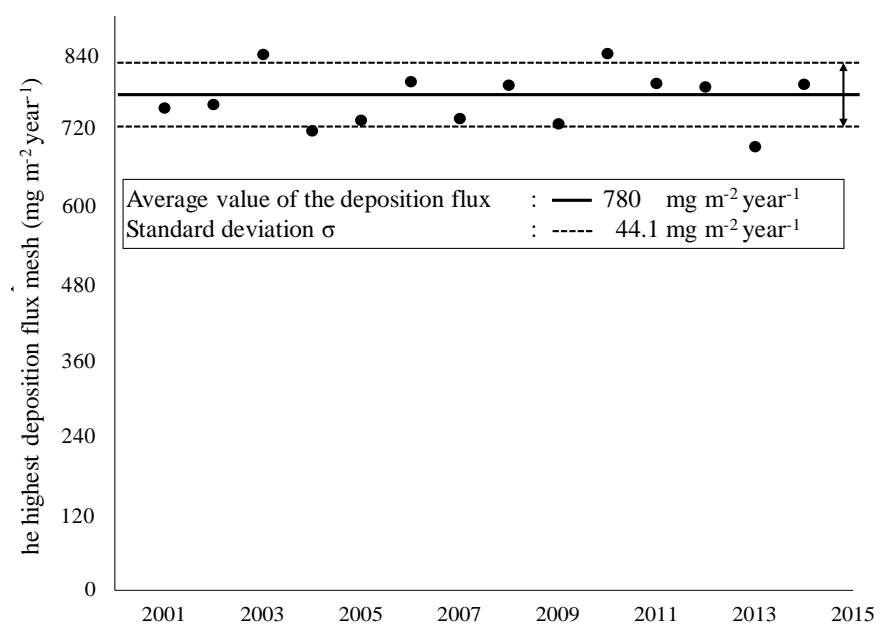

Figure 11. Annual variation of deposition flux due to climate fluctuation.

\section{Conclusions}

The horizontal distribution of surface soil polluted with $\mathrm{Pb}$ around a factory can be monitored by sampling surface soils and by using the ADMER model to simulate atmospheric deposition. At sites with a high estimated annual $\mathrm{Pb}$ deposition flux, the measured $\mathrm{Pb}$ content in surface soil samples ( $0-2 \mathrm{~cm}$ depth) was also high. As the distance from the emission source increases, the deposition flux and content tended to be smaller. There was good agreement between the estimated annual deposition flux and the distribution of soil's measured $\mathrm{Pb}$ content. Even at sites considered far from the $\mathrm{Pb}$ emission source $(>400 \mathrm{~m})$, where the possibility of soil pollution caused by leaking drainage water was low, the Pb content of the surface soil samples still exceeded Japan's legal limit. Therefore, a highly mobile form of $\mathrm{Pb}$, such as particulate matter could spread the $\mathrm{Pb}$ pollution. Based on the correlation between the measured and estimated levels of $\mathrm{Pb}$ pollution, sites near the emission source $(<680 \mathrm{~m}$ from the factory) tended to have larger values for measured $\mathrm{Pb}$ content than estimated $\mathrm{Pb}$ deposition; this result was obtained using a fixed particle size in the ADMER model, but varying particle size, the larger particles are deposited faster and closer. We found that even holding Pb emissions constant, the greater the size of emitted particles, the higher the amount of $\mathrm{Pb}$ deposited on the soil and the larger the polluted area. Therefore, in order to prevent soil pollution due to atmospheric $\mathrm{Pb}$ deposition, it is essential to monitor the amount of deposition on soils, and the distribution of areas polluted with $\mathrm{Pb}$-containing particles of various sizes. Lead pollution of soil is a stock type contamination, and therefore a long-term estimate of $\mathrm{Pb}$ deposition flux is necessary. In our long-term estimate, we evaluated annual fluctuation of the $\mathrm{Pb}$ deposition estimates in relation to changing meteorological data. Variations in deposition flux due to annual climate fluctuations were not significant for our case. However, the impact of climate fluctuations on deposition flux must be investigated in other factories and regions.

Acknowledgments: This work was supported by JSPS KAKENHI Grant No. 26281047.

Author Contributions: Binh Nguyen Thi Lan and Takeshi Kobayashi conceived and designed the experiments; Binh Nguyen Thi Lan performed the experiments; Binh Nguyen Thi Lan and Takeshi Kobayashi analysed the data and wrote the paper; Atsushi Suetsugu, Xiaowei Tian, and Takashi Kameya checked the paper and contributed important comments about analysis method and results.

Conflicts of Interest: The authors declare no conflict of interests. 


\section{References}

1. Japan Ministry of the Environment. Results of the Survey on the Enforcement Status of the Soil Contamination Countermeasures Act and Soil Contamination Investigations and Countermeasures in FY 2015. Available online: http:/ / www.env.go.jp/en/headline/2331.html (accessed on 2 October 2017).

2. Japan Ministry of Economy Trade and Industry. The Result of the Pollutant Release and Transfer Register (PRTR), 2015. Available online: http://www.env.go.jp/en/chemi/prtr/prtr.html (accessed on 2 October 2017).

3. Urrutia-Goyes, R.; Argyraki, A.; Ornelas-Soto, N. Assessing Lead, Nickel, and Zinc Pollution in Topsoil from a Historic Shooting Range Rehabilitated into a Public Urban Park. Int. J. Environ. Res. Public Health 2017, 14, 698. [CrossRef] [PubMed]

4. Gray, C.W.; McLaren, R.G.; Roberts, A.H.C. Atmospheric accessions of heavy metals to some New Zealand pastoral soils. Sci. Total Environ. 2003, 305, 105-115. [CrossRef]

5. Chen, T.; Zheng, Y.; Lei, M.; Huang, Z.; Wu, H.; Chen, H.; Fan, K.; Yu, K.; Wu, X.; Tian, Q. Assessment of heavy metal pollution in surface soils of urban parks in Beijing, China. Chemosphere 2005, 60, 542-551. [CrossRef] [PubMed]

6. United States Geological Survey. Lead in the Environment; QE516.P3L4 553'.44 76-7962; United States Government Printing Office: Washington, DC, USA, 1976.

7. European Commission ('DG Environment'). Science for Environment Policy; Soil Contamination: Impacts on Human Health; European Commission: Bristol, UK, 2013.

8. Benjamin, M.M.; Leckie, J.O. Multiple-Site Adsorption of $\mathrm{Cd}, \mathrm{Cu}, \mathrm{Zn}$, and $\mathrm{Pb}$ on Amorphous Iron Oxyhydroxide. J. Colloid Interface Sci. 1981, 79, 209-221. [CrossRef]

9. Al-Khashman, O.A.; Shawabkeh, R.A. Metals distribution in soils around the cement factory in southern Jordan. Environ. Pollut. 2006, 140, 387-394. [CrossRef] [PubMed]

10. Krishna, A.K.; Govil, P.K. Soil contamination due to heavy metals from an industrial area of Surat, Gujarat, Western India. Environ. Monit. Assess. 2007, 124, 263-275. [CrossRef] [PubMed]

11. Soriano, A.; Pallarés, S.; Pardo, F.; Vicente, A.B.; Sanfeliu, T.; Bech, J. Deposition of heavy metals from particulate settleable matter in soils of an industrialised area. J. Geochem. Explor. 2012, 113, 36-44. [CrossRef]

12. Qiao, P.; Lei, M.; Guo, G.; Yang, J.; Zhou, X.; Chen, T. Quantitative Analysis of the Factors Influencing Soil Heavy Metal Lateral Migration in Rainfalls Based on Geographical Detector Software: A Case Study in Huanjiang County, China. Sustainability 2017, 9, 1227. [CrossRef]

13. Kobayashi, T.; Liu, Y.; Takahashi, Y.; Kameya, T.; Yamada, Y. The Adsorption Equilibrium of Pb and Cd on Several Soils in Various pH Solutions or in the Presence of Dissolved Humic Substances. In Heavy Metal Contamination of Soils; Springer: Berlin, Germany, 2015.

14. Godin, P.M.; Feinberg, M.H.; Ducauze, C.J. Modelling of Soil Contamination by Airborne Lead and Cadmium around Several Emission Sources. Environ. Pollut. Ser. B 1985, 10, 97-114. [CrossRef]

15. Steinnes, E.; Solberg, W.; Petersen, H.M.; Wren, C.D. Heavy metal pollution by long range atmospheric transport in natural soils of Southern Norway. Water Air Soil Pollut. 1989, 45, 207-218. [CrossRef]

16. Zhang, G.; Yang, F.; Zhao, Y.; Zhao, W.; Yang, J.; Gong, Z. Historical change of heavy metals in urban soils of Nanjing, China during the past 20 centuries. Environ. Int. 2005, 31, 913-919. [CrossRef] [PubMed]

17. Cheng, $\mathrm{H}$.; $\mathrm{Hu}, \mathrm{Y}$. Lead $(\mathrm{Pb})$ isotopic fingerprinting and its applications in lead pollution studies in China: A review. Environ. Pollut. 2010, 158, 1134-1146. [CrossRef] [PubMed]

18. Hu, Y.; Liu, X.; Bai, J.; Shih, K.; Zeng, E.Y.; Cheng, H. Assessing heavy metal pollution in the surface soils of a region that had undergone three decades of intense industrialization and urbanization. Environ. Sci. Pollut. Res. Int. 2013, 20, 6150-6159. [CrossRef] [PubMed]

19. Benson, P.; Baishiki, R. CALINE3-A Versatile Dispersion Model for Predicting Air Pollutant Levels Near Highways and Arterial Streets; FHWA/CA/TL-79/23, NTIS: PB 220842; California State Department of Transportation: Sacramento, CA, USA, 1979; p. 129.

20. Rao, S.T.; Sistla, G.; Keenan, M.T.; Wilson, J.S. An evaluation of some commonly used highway dispersion models. J. Air Pollut. Control 1980, 30, 239-246. [CrossRef]

21. Rao, S.T.; Keenan, M.; Sistla, G.; Samson, P. Dispersion of Pollutants near Highways—Data Analysis and Model Evaluation; EPA-600/479-011; U.S. Environmental Protection Agency: Washington, DC, USA, 1979. 
22. Brandt, J.; Christensen, J.H.; Frohn, L.M. Modelling transport and deposition of caesium and iodine from the Chernobyl accident using the DREAM model. Atmos. Chem. Phys. 2002, 2, 397-417. [CrossRef]

23. Chino, M.; Nakayama, H.; Nagai, H.; Terada, H.; Katata, G.; Yamazawa, H. Preliminary Estimation of Release Amounts of ${ }^{131} \mathrm{I}$ and ${ }^{137} \mathrm{Cs}$ Accidentally Discharged from the Fukushima Daiichi Nuclear Power Plant into the Atmosphere. J. Nuclear Sci. Technol. 2011, 48, 1129-1134. [CrossRef]

24. Higashino, H.; Inoue, K.; Mita, K.; Shinozaki, H.; Yoshikado, H. Atmospheric Dispersion Model for Exposure and Risk assessment (ADMER) development and verification of nationwide version. Environ. Manag. 2004, 40, 1242-1250. (In Japanese)

25. Higashino, H.; Inoue, K. Development of an Atmospheric Dispersion Model for Exposure and Risk Assessment (ADMER) Ver. 3. Jpn. J. Risk Anal. 2016, 26, 41-46. [CrossRef]

26. Higashino, H.; Mita, K.; Yoshikado, H.; Iwata, M.; Nakanishi, J. Exposure and risk assessment of 1,3-butadiene in Japan. Chem.-Biol. Interact. 2007, 166, 52-62. [CrossRef] [PubMed]

27. Japan Ministry of Economy Trade and Industry. The Result of the Pollutant Release and Transfer Register (PRTR), 2001-2014. Available online: http:/ / www.env.go.jp/en/chemi/prtr/prtr.html (accessed on 2 October 2017).

28. Japan Ministry of the Environment. Environmental Quality Standards for Soil Pollution. Available online: http:/ / www.env.go.jp/en/water/index.html (accessed on 2 October 2017).

29. The Lead Content in the Soil Was Measured by the Japan Ministry of the Environment, Notification N.19, 2004. (In Japanese). Available online: http:/ / www.env.go.jp/hourei/06/000029.html (accessed on 2 October 2017).

30. Higashino, H.; Kitabayashi, K.; Inoue, K.; Mita, K.; Yonezawa, Y. Development of an atmospheric dispersion model for exposure and risk assessment (AIST-ADMER). J. Jpn. Soc. Atmos. Environ. 2003, 38, 100-115. [CrossRef]

31. Maenhaut, W.; Zoller, W.H.; Duce, R.A.; Hoffman, G.L. Concentration and size distribution of particulate trace elements in the south polar atmosphere. J. Geophys. Res. 1979, 84, 2421-2431. [CrossRef]

32. European Monitoring and Evaluation Programme (EMEP). Heavy Metals and POP Measurements, 2004; Norwegian Institute for Air Research: Kjeller, Norway, 2006; p. 20.

33. Yoshinaga, J. Lead in the Japanese living environment. Environ. Health Prev. Med. 2012, 17, $433-443$. [CrossRef] [PubMed]

34. Sakata, M.; Marumoto, K. Dry deposition fluxes and deposition velocities of trace metals in the Tokyo Metropolitan Area Measured with a Water Surface Sampler. Environ. Sci. Technol. 2004, 38, 2190-2197. [CrossRef] [PubMed]

35. Noll, K.E.; Fang, K.Y.P. Development of a Dry deposition model for atmosphere coarse paticles. Atmos. Environ. 1967, 23, 585-594. [CrossRef]

36. Japan Ministry of the Environment. Soil Contamination Countermeasures. Available online: http:/ / www. env.go.jp/en/water/soil/contami_cm.pdf (accessed on 2 October 2017).

(C) 2018 by the authors. Licensee MDPI, Basel, Switzerland. This article is an open access article distributed under the terms and conditions of the Creative Commons Attribution (CC BY) license (http://creativecommons.org/licenses/by/4.0/). 